\title{
STAYING ALIVE WITH DANCE! SELF-CARE FOR WOMEN
}

\section{Madhu Kasiram, Ashika Sookoo, Brenda Ilbury, Shobha Pais}

\section{INTRODUCTION}

This article reports on a two-phase study involving women, self-care and dance: the first phase used a sample of women dancers and the second used aerobics instructors to illuminate what was found in the first phase.

The first phase results have already been sent for publishing, so the focus here is on the second phase, but key findings from phase one are also incorporated to some extent in order to provide a context for the second phase.

Women are the classic nurturers in society, but their roles are now multi-fold with little time and attention afforded to self-care (Pais \& Kasiram, 2007). In addition to child rearing, many women have become key breadwinners and leaders, relegating some of the responsibility of nurturing to significant others, whilst frequently maintaining covert control of this function. As a result women's lives are complex and busier than ever before with multi-tasking becoming necessary for their survival. Compounding this scenario is the pressure of looking good and keeping healthy in a globally networked world where monogamous relations are not always accorded respect and sanction. Thus society and women, now more than ever, see the need for engaging in self-care to rejuvenate body and soul, to receive strength and health, and to continue with the pressures of living productively in the face of burnout (Khosa, 2007). Caretaking and care giving are stressful functions, especially to those affected by HIV and AIDS. Dance, music and dramatic expression provide culture-specific ways for catharsis and renewal, and may be easily accessed in resource-poor communities (Kasiram \& Oliphant, 2005).

Phase one of the study by Kasiram, Patel, Ilbury and Pais (2007) established the popularity of dance, music and rhythm for managing stress, promoting physical and mental wellbeing and for overall self-care amongst women attending a dance class, dance being a recognised art form for stress release (Corbin \& Metal-Corbin, 1997). In the second phase, the focus of the paper, gym instructors' views were elicited to build up a comprehensive picture of how dance may be optimally used and taught as a self-care strategy.

\section{Scope of the study}

The scope of the full study encompassed:

- what women want from dance aerobics classes (phase one);

- how instructors can best provide this (phase two).

The second phase explored focus areas commensurate with those of phase one, viz. atmosphere in the class; music; dance routine; and instructor characteristics. In phase two the instructor was the target - understanding how she promoted attendance and enjoyment of the class in respect of these categories. The following key questions were used in exploring these focus areas:

- How can atmosphere, music and moves/choreography in a dance aerobics class be optimally harnessed to sustain motivation to attend?

- What is it that happens in dance aerobics that rejuvenates and energises women?

- How can instructors provide an effective dance exercise experience for all women? 


\section{Value of the study}

The general queries levelled at the researchers/authors relate to how "fun and dance" relate to academic, objective study and social work practice.

Our response is as follows:

- Self-care, being crucial to both service providers and recipients, needs to be innovative to keep alive and sustain effect, and if it has the additional benefit of being fun, then there should be no guilt attached to researching this too;

- Social work respects the diversity of human need, culturally, socially and economically. So too there is diversity of needs amongst women, with no two women having the exact same preferences regarding self-care. This study researches an avenue of self-care that has been academically under-researched and under-recognised, meeting as well as recognising the diversity of female self-care expression;

- Research often derives from personal experience of a situation, which was the case for the researchers, who found there to be enormous benefits in attending dance class regularly;

- The study was objective and results point to learning edges in social work and psychology, viz. on self-care among women, for sports science in appreciating how best to teach and train for optimal bio-psycho-social benefit, and for health science in establishing the significant role of dance as an adjunct to other traditional remedial and preventive healthpromoting measures;

- Social work is essentially a helping, healing art. By evaluating the empowering effects of dance for self-care, the profession can potentially meet the aim of primary prevention amongst women as a special population with different and specific needs in self-care. Researching achievable activities that are empowering to female self-care is consistent with our need to give (female) clients a range of vehicles that empower, stimulate, maintain and inspire;

- Our aim as a profession is to empower, in other words to enable people to achieve optimal states of holistic well being with minimal reliance on "clinical" therapies. This study shows how dance may be a vehicle that can promote such holistic well being.

\section{Research methodology}

The first phase of the study utilised both qualitative and quantitative components as the intention was to secure a quick quantitative overview, using a questionnaire (Babbie \& Mouton, 2001) to explore experience in a specific dance class known to the researchers. A few open-ended questions comprised the qualitative component within the questionnaire. The goal of this phase of the project was to determine the viability of dance, music and rhythm for managing stress, promoting physical and mental wellbeing and overall self-care.

The second phase of the study was qualitative, specifically using the descriptive and exploratory paradigms to intensively examine the phenomenon of dance from the instructor's perspective (De Vos, Strydom, Fouche \& Delport, 2005). The research tool was focus group discussions conducted at a workshop. Different questions were posed to each focus group on the key areas outlined in phase one of the study. A report-back segment allowed for groups to share their views so that ultimately the benefits were both in engaging intensively with one focus area and hearing views of others on remaining areas. 


\section{The sample}

It is noteworthy that both the class where the questionnaire was administered and the workshop were attended by women only. So although men were not excluded, their non-attendance in both settings precluded their participation and their voices from being heard in this study. Perhaps this is evidence that there is something in this exercise type that appeals to and attracts the feminine spirit. This also points to the fact that women have different needs and preferences in self-care than men do and that dance is a vehicle that is effective in meeting these needs. Thus social work as a helping profession needs to recognise and further research the value of dance as a preferred method of female self-care.

The locale for both phases was a gym franchise in the Durban area of KwaZulu-Natal, South Africa, where some of the researchers/authors had membership, so access for participants was not problematic. The sample was a convenient and available sample, but represented a whole class of gym goers $(\mathrm{N}=40)$ and all instructors as participants $(\mathrm{N}=20)$ at the workshop. Thus limited generalisability is permissible to other dance attendees and instructors. At this stage, suffice it to say that gathering rich descriptive data was the concern to better appreciate an exercise form that may lend itself to further rigorous research later.

\section{The research process}

Instructors were appraised of the findings from phase one of the study to alert them to gym goers' needs and frustrations relating to the four focus areas. This was done to kick-start discussion from the perspective of gym attendees and use time economically to arrive at best teaching, learning and dance enjoyment ideals.

\section{Results and discussion}

Results are discussed in accordance with the objectives mentioned earlier. Objective 3 is incorporated into the other objectives as the study focus in phase two was on instructors providing an optimal dance experience.

\section{Atmosphere in the dance class}

In the first phase women wanted the class atmosphere to be "stimulating, energizing and fun" (Kasiram et al., 2007). High energy stimulates enjoyment and promotes rejuvenation, enabling the feminine spirit to lose itself in enjoying the moment and not "fret about multiple responsibilities". From a systems perspective it seems that women feed off positive energy in the dance aerobics class, which enlivens them and gives them strength to cope with other aspects of their lives. This "in the moment" enjoyment also reaches what many social work and allied therapies aim to achieve in stressed and multi-tasking women - introspective focus and time for self in the midst of multiple responsibilities. This indicates a need for further research into the dynamics between exposure to a positive high-energy atmosphere and stress relief in women.

Instructors too discussed the importance of a stimulating, enjoyable atmosphere that was not inhibiting. Communication and good teaching skills were identified by instructors as vital in setting a fun and high-energy atmosphere. They clearly recognised the liberating appeal of a high-energy atmosphere, commensurate with findings from phase one. Warm greetings, using members' names wherever possible, and touch and eye contact were considered important. The suggestion was to use name tags to get to know attendees. Clearly the vehicle of a solid relationship to enable teaching to occur with confidence was valued and also discussed by Miller and Duncan in their study of "what works well in therapy" (2008). A further core 
ingredient in assuring success is to offer options for beginner/advanced and intermediate levels. This option needs to be carefully worded so as to label the options rather than the attendees. In addition, the need for teaching deliberately using a pyramid system, starting slowly and adding intensity, whilst making room for "recoveries", were all regarded positively, in accordance with sound pedagogical-didactical principles (Steyn, Wolhuter, Oosthuizen \& Van der Walt, 2003). These teaching and learning suggestions may well be incorporated by the innovative social worker who wishes to incorporate teaching into her repertoire of interventions, specifically in introducing dance as an adjunct to professional services to clients.

Ideally, attendees should be able to keep up with a class and value it, and instructors were cognisant of this. Thus instructors set the scene for the therapeutic dance process to occur by creating a relaxed, comfortable atmosphere using sound learning and teaching strategies.

When asked what would encourage members to return to the class, instructors again identified communication as key: "encourage members to come back and finish class next week; ask class what they want from the class; be approachable; energetic and inspirational; encourage class to give you feedback; educate them about the class type; communicate to set goals with the class and to ensure that class goals are congruent with member goals".

In both phases the process goal of having fun was accorded great value, with no one citing the traditional exercise motivators or outcome goals of losing weight or gaining muscle strength as motivating attendees to return to the class. Thus the overt object of the class, for both instructor and women gym attendees, is not to lose weight, target and tone specific body areas, improve heart rate, etc., but to enjoy the dance process. We conclude from this that for both sample groups the process of dancing itself is therapeutic - it enables women to have fun, become rejuvenated, de-stressed and be fully in the moment. Note is taken of the possibility of using dance to help women rejuvenate in order to release blocks that prevent them from focusing/attending or from being overwhelmed by multiple responsibilities. Indeed, dance could be introduced into community projects to bring people together and facilitate shared vision and goal aspiration. Sliep (2006) refers to narrative theatre that educates whilst empowering HIV-positive women. Perhaps, culture-sensitive and specific dances could be added to this intervention and preventive option to bring in a "fun" element to the experience.

\section{Music and dance success}

Gym goers had indicated in phase one that music was important to get into the dance mode and "let oneself go". As discovered by scientists at Ohio State University in the US, moving to the rhythm of a classical beat improves verbal skills and speeds up thought processes and mental alertness (Parker, 2004:14). It is possible, though not researched in this study, that dancers and their instructors covertly or overtly experienced similar benefits that kept them returning to dance classes.

Instructors clearly identified music as a key element in the success of the class and choreography as it is "inspirational". They identified music as creating a fun, happy and connecting atmosphere, qualifying that "rhythm is universal" and that it can be enjoyed regardless of class, culture, race, etc. These findings directly relate to what women said in the first phase about how music stimulates enjoyment of a dance class.

Instructors were challenged to reflect on how music may reach all members regardless of differing ability levels. Their own preferences, the dance class type, class identifying with the music and demographics of the dancers were all identified by instructors as important determinants in choosing music. They suggested that a survey on the music that members want 
to hear and mixing music styles or eras in one class would ensure enjoyment of the music and translate to class success.

Instructors also identified technical factors as being important such as good-quality sound systems that needed to be in prime working condition, suitable placement of speakers, and availability of a microphone as instrumental in ensuring good attendance. Should a service provider consider using dance as an adjunct to therapy, these core essentials should not be disregarded. In a context where infrastructural constraints render many of these essentials unavailable, contingency plans must be made, as the success of the encounter is highly dependent on hearing/relating to the selected music well for the dance to be learnt and taught effectively.

Music is a known de-stressor. The role of music in stress relief is an established one "Listening to music or playing a musical instrument activates the brain's pleasure centers, which may help lower blood pressure, improve sleep and reduce pain, depression and anxiety" (Younghusband, 2007:20).

Both dance and music can offer stress relief. Women can achieve a double dose of stress relief and therapeutic benefits via the anxiety-reducing qualities of music combined with the moodenhancing qualities of energetic exercise that are present in one dance class. How best to teach and use music were important factors in ensuring that these goals were achievable. Implications for helping professionals are varied in that music alone or together with dance may well be used in concert with traditional remedies/interventions to enliven and enthuse stuck clients who are too afraid to take steps to change. This may mean using dance and music with a group of disempowered women to re-author their stories of pain, and the group encounter accompanied by music and/or dance that is selected and controlled by them could provide a creative symphony where helping and healing may be promoted.

The value of music and movement and non-verbal therapies is recognised by social workers who use play therapy and dance movement therapy. However, the findings indicate that some of the powerful therapeutic value of these modalities can also be achieved outside the clinical arena by the simple and comparatively inexpensive incorporation of dance into women's selfcare routines.

\section{Choreography and dance success}

In phase one women stressed the importance of "high activity and energy" in choreography to "improve physical health and attitude" and "sustain one for the rest of the day".

Instructors similarly identified positive energy projected through their personality as significant in choreography and in ensuring class success. To overcome resistance in members who may feel threatened or embarrassed, and to keep choreography fresh and challenging, various forms of encouragement were cited: maintaining eye contact with the class; assurance that there is no right or wrong movement; smiling; verbal urging; a positive attitude and keeping choreography basic and do-able whilst giving add-on options. Avoiding routine moves and phrases that are repetitive was also important. So, keeping a fresh perspective in order that boredom does not prevent regular practice was key and has strong implications for helping personnel who also need to work creatively and differently to challenge old and sometimes dysfunctional patterns. Kasiram, Smith, Engelbrecht and Partab (2009) found that practitioners sometimes unconsciously revisit the same theory frames without regard for creativity to inspire change. Dance may provide such a fresh and creative outlet to stimulate change among clients locked in and by their practitioners' therapeutic styles. Instructors clarified the need for dancers to feel 
that they are achieving, learning and progressing in the class. Sound behaviourist principles are evident in this in sustaining attendees and keeping them motivated (Chaplain, 2003; Louw, 1991) and have relevance for recipients of social work and health services.

Instructors noted that ultimately members needed to connect with the instructor and themselves - related to getting to know their bodies better to make optimal use of the choreography.

Results from both phases show that women look for energy, fun and enjoyment in dance, and instructors see these factors as important aspects of the choreography of successful dance classes. Usually any person who engages in regular physical activity shows more desirable health outcomes across a variety of physical conditions including better general and healthrelated quality of life, better functional capacity and better mood states (Penedo \& Dahn, 2005). Physical activity is known to increase special neurotransmitter substances in the brain (endorphins), which create a state of wellbeing. Total body movement such as dance enhances the functions of other body systems, such as circulatory, respiratory, skeletal and muscular systems. Dance may be regarded as a healing art, based on the premise of the mind and body as a gestalt in which change in one of these domains produces a corollary change in the other. The neurophysiological responses from dance and movement therapy have been shown to promote healing and alter affect in both individuals and groups (Berrol, 2006). Other studies have shown that aerobic exercise training may be useful for reducing the severity and duration of depressive reactions following stressful life change (Roth \& Holmes, 1987). Significant short-term positive mood changes have also been noted after participating in modern dance classes (Lane, Hewston, Redding \& Whyte, 2003). A study by McInman and Berger (1993) examined the relationship between short-term changes in self-concept and mood associated with aerobic dance participation. They found that emotional stability self-concept, physical appearance selfconcept, and global self-concept correlated moderately with specific dimensions of mood. These findings have relevance for social work, especially in individual, group and community mood uplift, and can harness the temporary change experienced for planning long-term and sustainable change strategies.

Energetic dance is clearly a popular vehicle that enables women to let go of inhibitions, relax into the dance and feel the benefits of the choreographed movements. Because the personality of the instructor is a vital factor in choreography, the instructor's personality must be "projected as good energy" via the choreography. It seems that women feed off the energy of the instructor in executing the moves and are energised by this process (Kasiram et al., 2007). Used therapeutically, dance can enhance the emotional, social, spiritual and physical integration of the individual (Brody, 1995). Helping professionals seriously need to take cognisance of these benefits and not regard dance, rhythm and music as merely fun and hence not sufficiently academic to warrant their employing it as an adjunct to therapy.

\section{Rejuvenation through connection}

Related to the choreography was an interesting finding about connection in both phases. Both dancers and instructors said that effective communication and presenting as connected beings was important for enjoyment and teaching success. All these women indicated that they seek human connection through movement and exercise, and are rejuvenated by this connection. Of note is the fact that men choose not to attend this class, which further reinforces the importance of the human connection via dance for women; women (dancers and instructors alike) are recharged by the positive presence of others. 
Connection via dance may be found in:

- Connection with the instructor who guides the member into dance and encourages the member and the class;

- Synchronised group movement is the means of creating connection within the group. Others give off energy through movement. This produces an atmosphere of energy, fun and camaraderie. The group feeds off this atmosphere and the individual is energised by this;

- Introspective connection of the female individual with herself via the dance moves - the member gets to know her body better via the dance and lets herself go in the dance.

This finding is significant as it implies that women more than men need to connect within themselves and outside of themselves. Working women in particular may feel isolated in a male dominated world and may well be referred to enjoy such connection (through dance) to recharge herself and relate comfortably to other women. Indeed, Sookoo (2008) found in her study of belly dance that women wanted to reclaim being women in a male-dominated world, through belly dance, as this dance form specifically focused on their sensuality, sexuality and feminine dress, all of which were open to male scrutiny and judgement in their everyday lives. The question is, then: what is the combined effect of years of repression of the female spirit and how can practitioners help women find themselves again without censure and guilt?

This finding also shows that, contrary to popular societal opinion of women being envious and competitive with each other, women actually accept each other and value and gain benefits from each other's company. This study shows that this dynamic exists in the non-verbal modality of dance in the absence of men. The self-care value of inter-female connection gives credence to the therapeutic effects of women's groups, girls' nights out, hen parties, bridal showers and other female social activities, giving practitioners permission to encourage these activities. This also shows a need to further research the value of all-women groups in therapeutic group work, particularly with females battling with poor body image, low selfesteem and weak self-confidence.

\section{Characteristics of a successful dance instructor}

A happy, motivated, inspiring, patient, friendly and attentive instructor who simultaneously motivates old and young to give of their best, and to enjoy and benefit from the workout were considered important by dancers in phase one of the study.

In phase two the instructors paralleled the dancers' responses - they felt that successful dance instructors are enthusiastic, positive, approachable, energetic and inspirational. Instructor responses included the technical skills of having teaching skills and "musicality" - being able to count music as important. They also regarded communication, complimenting members, being humorous, smiling, maintaining eye contact, reminding them they are not being watched by others and general encouragement as inspirational. They also suggested that joining as a member in some classes may facilitate relationship building with members.

It is interesting to note that the desired personality traits of successful instructors are synonymous with the positive qualities traditionally identified with exercise - happiness, inspiration, motivation and positive attitude. Perhaps learning edges for helping professionals are not far removed from these features as tired, belligerent and demotivated personnel could well begin a journey of self-care and rediscovery before referring their clients for the same. Self-caring for service practitioners is gaining in significance as we struggle to do more with 
less, and it is being increasingly recognised as a crucial component of the social work curriculum (Kasiram, 2008).

\section{Conclusion - the therapy of dance}

The two-part study established that dance, music and rhythm are effective in self-care, particularly amongst women. Future studies could include men, a larger sample and mixing methodologies in order to make more valid generalisations and to understand gender variations better. Practitioners may thus be encouraged to use these universal tools in managing their own stress and that of their clients. Dance bypasses verbal ability, effectively achieving the therapy of rejuvenation of the body as well as the soul. A dance class does not happen in a vacuum. There is energetic connection with the instructor and with others via the combination of music, choreography, atmosphere and instructor. In this regard, specific conclusions that may encourage practitioners to more readily use dance as an adjunct to therapy include:

- Women are traditionally regarded as sensitive to emotion. This study shows that women are also energetically and systemically sensitive. They are able to sense and to feed off the positive vibes and the positive energy, encouragement and sense of fun of the instructor. Thus the instructor's happiness, enjoyment and high energy are easily picked up by women, who are energised by it. This finding shows us the dire need for self-care for female practitioners working long hours in stressful and trauma-exposing environments in order to put back what the job has taken out.

- In this study energetic dance proved to be a vehicle for positive energy exchange as a key goal of class attendance. It was significant that women did not rate change in body image issues as significant for class success. Scant attention to poor body image in the results shows that dance leads to a positive self-concept that is independent of the physical in women. Women who dance for exercise are motivated by the process goals of enjoyment, fun and energy, and by the outcome goal of rejuvenation and not by body image issues. This shows us that women value a self-care vehicle that operates intra-psychically to promote self-acceptance. The lesson for social workers is that rejuvenation rather than health is often felt as a need of some women. Such a simple oversight may lead both the woman and her family to focus on irrelevant goals, with disastrous therapeutic outcomes.

- Women demarcate their lives and their time in terms of their social obligations, the most prominent of which is family. Thus they define themselves and their roles socially or in relation to other people. As women seem to exist in relation to others, they are best rejuvenated by the positive presence of others that is provided by the dance class. The presence of other happy women giving off positive energy in the dance class creates a positively charged social atmosphere that is recognisable, appropriate and effective to serve a therapeutic function. It is an easily accessible, inexpensive resource that may be employed by social workers.

- A high-energy, fun, "vibey", relaxed atmosphere, the presence of rhythmic music, an inspiring, happy instructor and energetic and enjoyable choreography enable women to let go and be in the dance. Women can reclaim becoming human "beings" and not human "doings" taking no time for the self or simple pleasures (Kasiram \& Oliphant, 2005). Their multiple roles and obligations can thereby be temporarily forgotten (and later resumed with better concentration) as they dance, dance, dance! 


\section{REFERENCES}

BABBIE, R. \& MOUTON, J. 2001. The practice of social research. Cape Town: Oxford University Press.

BERROL, C.F. 2006. Neuroscience meets dance/movement therapy: mirror neurons, the therapeutic process and empathy. The Arts in Psychotherapy, 33(4):302-315.

BRODY, J.E. 1995. Personal health. Houston Chronicle, 22:4.

CHAPLAIN, R. 2003. Teaching without disruption in the secondary school - a model for handling pupil behaviour. United Kingdom: MPG Books.

CORBIN, D.E. \& METAL-CORBIN, J. 1997. Reach for it: a handbook of health: exercise and dance activities for older adults $\left(3^{\text {rd }}\right.$ ed). Peosta, IA: Eddie Bowers Publishing Inc.

DE VOS, A.S., STRYDOM, H., FOUCHÉ, C. \& DELPORT, C. 2005. Research at grassroots for social sciences and human service professions. Pretoria: Van Schaik Publishers.

KASIRAM, M. \& OLIPHANT, E. 2005. Challenges and changes to family therapy practice in South Africa. AFTA Monograph Series. Lessons learned in Community Practice, 1(2):33-39.

KASIRAM, M., PATEL, C., ILBURY, B. \& PAIS, S. 2007. When the going gets tough: the tough need dance! Paper presentation. Florence, Italy, June 2007.

KASIRAM, M. 2008. An exploratory study of international migration and employment of social workers. Paper presentation at IASSW Conference, Durban, July 2008.

KASIRAM, M., SMITH, A., ENGELBRECHT, C. \& PARTAB, R. 2009. Against all odds: family therapy in South Africa. Poster presentation at the IFTA Conference. Slovenia, March 2009.

KHOSA, V. 2007. Responses on non-governmental organisations to the needs and expectations of volunteer trauma support workers within the victim empowerment sector in KwaZulu-Natal. Durban: University of KwaZulu-Natal. (Unpublished Masters Dissertation)

LANE, A., HEWSTON, R., REDDING, E. \& WHYTE, G. 2003. Mood changes following modern dance classes. Social Behaviour and Personality: An International Journal, 31(5):453-460.

LOUW, D.A. (ed) 1991. Human development. Pretoria: Haum Publishers.

McINMAN, A.D. \& BERGER, B.G. 1993. Self concept and mood changes associated with aerobic dance. Australian Journal of Psychology, 45:134-140.

MILLER, S. \& DUNCAN, B.L. 2008. What works in therapy. [Online] Available: WWw.talkingcure.com. [Accessed: 06/03/2008].

PAIS, S. \& KASIRAM, M. 2007. Self care: an important ingredient in responsible service provision. Presentation at the World family Conference, Prague, 17 May.

PARKER, H. 2004. Stress Tips. Shape Magazine, 14 June.

PENEDO, F.J. \& DAHN, J.R. 2005. Exercise and well-being: a review of mental and physical benefits associated with physical activity. Current Opinion in Psychiatry, 18(2):189-193. 
ROTH, D.L. \& HOLMES, D.S. 1987. Influence of aerobic exercise training and relaxation training on physical and psychological health following stressful life events. Psychosomatic Medicine, 49(4):355-365.

SLIEP, Y. 2006. Seeing HIV/AIDS through a social health lens: narrative theatre as a community based HIV/AIDS strategy. In: KASIRAM, M., PARTAB, R. \& DANO, B. HIV/AIDS in Sub-Saharan Africa; the not so silent presence. Pinetown, Durban: Print Connection.

SOOKOO, A. 2008. Belly dance as a self care strategy for women. Durban: University of KwaZulu-Natal. (Unpublished masters research dissertation)

STEYN, S.C., WOLHUTER, C.C., OOSTHUIZEN, I.J. \& VAN DER WALT, J.L. 2003. 'n Internasionale perspektief op leerderdissipline in skole. South African Journal of Education, 23(3):225-232.

YOUNGHUSBAND, T. 2007. Notes on anxiety. Shape Magazine, 20 July.

Prof Madhu Kasiram, School of Social Work and Community Development; Ms Ashika Sookoo, Postgraduate Student, School of Social Work and Community Development, University of KwaZulu-Natal, Howard College Campus, Durban, South Africa.

Ms Brenda Ilbury, Private Social Work Practitioner, Westville, Durban, South Africa.

Dr Shobha Pais, Director Behavioural Science, Indiana University Family Medicine Residency Program, Department of Family Medicine, Indiana University, 1520 North Senate Avenue, Indianapolis, IN 46202, USA. 